\title{
Validation Of The Total Resistance Model For Heat Transmission Through Longitudinal Fins With Variable Heat Transfer Coefficient
}

Ziad M. Al-Makhyoul - Assistant Lecture

\section{Department of Mechanical Engineering -University of Mosul - Iraq}

\begin{abstract}
The present paper outlines analytical investigation of the validity of total resistance model suggested by Kahwaji [4] for the heat dissipation when applied to longitudinal fins, the model will be as given in equation (22). Three distributions of heat transfer coefficient were used and represented as power, linear and exponential distributions to proved the validity of total resistance model at any variable heat transfer coefficient. Further more, a finite difference solution is devised to serve too the two purposes of verifying the two dimensional heat transfer and to cover wide range of variable and compare with the analytical solution. The results were agreement and proved the validity of the suggestion equation model above using the variable heat transfer coefficient and this model can be used in the constant or variable heat transfer coefficient in the heat transfer calculation for longitudinal fin.
\end{abstract}

Key words: longitudinal fin, variable heat transfer coefficient, total resistance

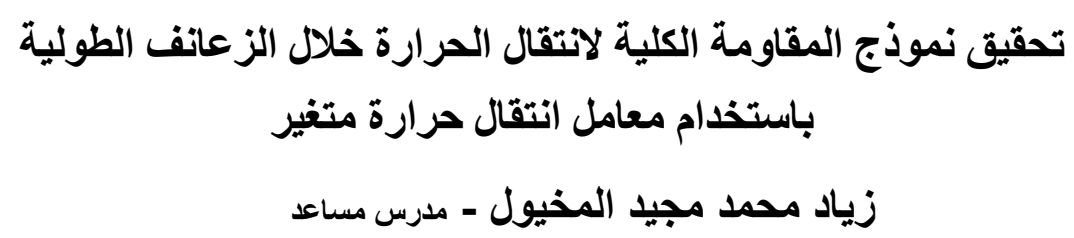

كلية الهندسة ـ قسم الهندسة الميكانيكية - جامعة الموصل

الخلاصة

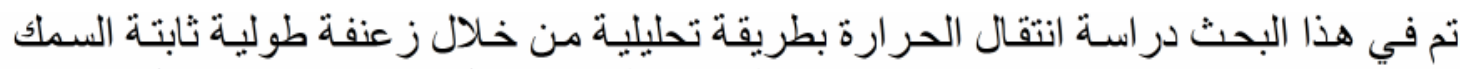

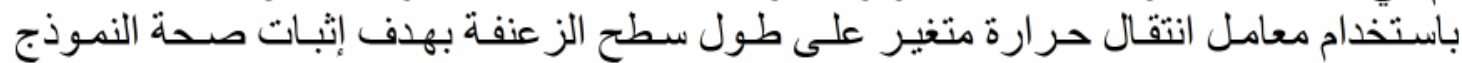

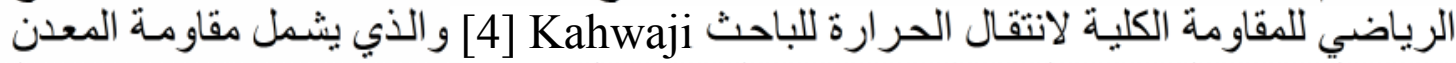

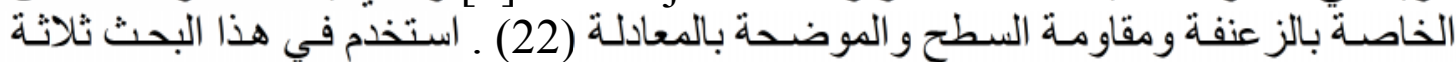

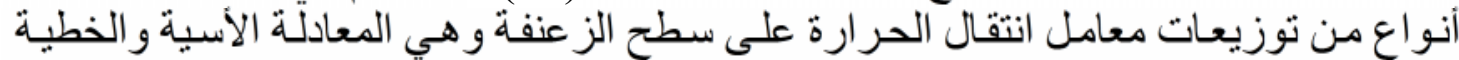

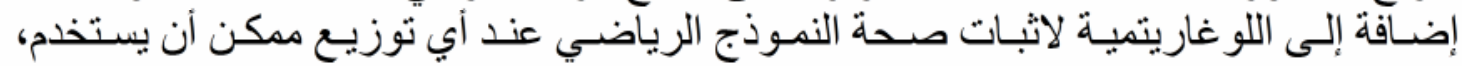

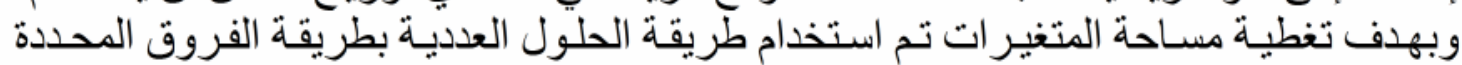
للز عنفة الطولية بالاتجاهين القطري و المستعرض باستخدام الأنواع الثناثة لمعامل انتقال حرارة الثرة 


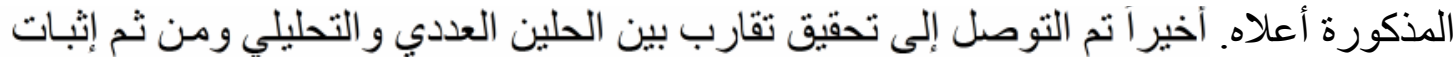

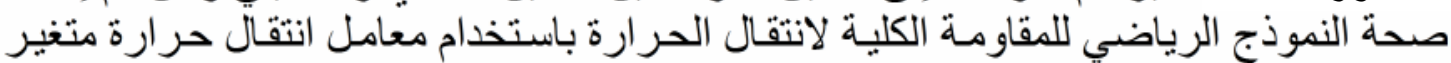

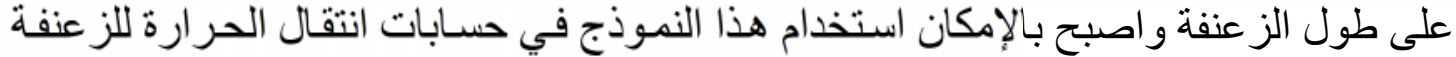

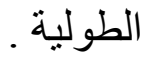

\section{Nomenclature:}

ha $\quad$ Heat transfer coefficient $\left(\mathrm{W} / \mathrm{m}^{2} .{ }^{\circ} \mathrm{C}\right)$

$\underline{\mathrm{H}} \quad$ Third dimension of fin (m)

$\underline{\mathrm{H}(\mathrm{x})} \quad$ Local heat transfer coefficient $\left(\mathrm{W} / \mathrm{m}^{2} .{ }^{\circ} \mathrm{C}\right)$

K $\quad$ Thermal conductivity $\left(\mathrm{W} / \mathrm{m} .{ }^{\circ} \mathrm{C}\right)$

$\underline{\mathrm{L}} \quad \underline{\text { Length of fin }(\mathrm{m})}$

$\underline{\mathrm{M}} \quad$ Number of grid in transverse direction

N Number of grid in longitudinal direction

QF Heat transfer from fin numerically (W)

QMax Maximum Heat transfer from fin numerically (W)

$\underline{Q}_{\text {the }} \quad$ Heat transfer from fin theoretically (W)

$\underline{r_{i}} \quad$ Inner radius of annular fin $(\mathrm{m})$

$\underline{\mathrm{R}}_{\mathrm{L}} \quad$ Longitudinal resistance of fin $\left({ }^{\circ} \mathrm{C} / \mathrm{W}\right)$

$\underline{\mathrm{R}}_{\underline{\mathrm{m}}} \quad \underline{\text { Material resistance of fin }\left({ }^{\circ} \mathrm{C} / \mathrm{W}\right)}$

$\underline{\mathrm{r}}_{\mathrm{o}} \quad$ Outer radius of annular fin $(\mathrm{m})$

$\underline{\mathrm{R}}_{\mathrm{S}} \quad \underline{\text { Surface resistance of fin }\left({ }^{\circ} \mathrm{C} / \mathrm{W}\right)}$

$\underline{\mathrm{R}}_{\mathrm{t}} \quad \underline{\text { Tangential resistance of fin }\left({ }^{\circ} \mathrm{C} / \mathrm{W}\right)}$

$\underline{\mathrm{T}}_{\mathrm{b}} \quad$ Base temperature $\left({ }^{\circ} \mathrm{C}\right)$

$\underline{\mathrm{T}}_{\mathrm{f}} \quad$ Fluid temperature $\left({ }^{\circ} \mathrm{C}\right)$

$\underline{\mathrm{TR}}_{\text {the }} \quad$ Total resistance theoretically $\left({ }^{\circ} \mathrm{C} / \mathrm{W}\right)$ 


\section{Introduction:}

Fins or extended surfaces are widely use to augment the rate of heat transfer from the primary surface to the ambient medium in a large variety of thermal equipment. It has long been known that the rate of heat transfer from a hot body to cooler fluid may be increased by extending the body surface. Furthermore, the addition of fins extending into the fluid will cause an increased heat flow not directly proportional to the increase in body surface, since the temperature near the tip of the fin approaches the fluid temperature and causes a heat rate less than that witch might be anticipated.

Han \& Lefkowits [1] confirmed that the assumption of uniform heat transfer coefficient is unrealistic. They assumed a power series distribution of the average heat transfer coefficient as shown in equation (1), to find the temperature distribution and the fin efficiency for straight fins, that is:

$$
\mathrm{h}(\mathrm{x})=(\gamma+1) * \mathrm{ha} *\left[\frac{\mathrm{x}}{\mathrm{L}}\right]^{\gamma}
$$

Where $(\gamma)$ is constant, (L) is the fin length and (ha) is the average heat transfer coefficient.

Chen and Zyskowiski [1] carried out the same work above with an exponential variation in the form of:

$$
h(x)=h a * \frac{1-a e^{-\left(\frac{c}{L} x\right)}}{1-\left(\frac{a}{c}\right) *\left(1-e^{-c}\right)}
$$

where (a and c) are constant, (L) is length of fin. 
Gardner [1] explained the temperature distribution for the longitudinal fin of rectangular profile using variable heat transfer coefficient and given this equation as:

$h(x)=h a * \frac{(1+a)\left(\frac{x}{L}+c\right)^{a}}{\left[(1+c)^{a+1}-c^{a+1}\right]}$

where (a) and (c) are constants.

Kundu \& Das [2] studied the analysis and optimization of straight taper fins with variable heat transfer coefficient along the fin surface. They determined analytically the temperature profiles for longitudinal fin, spine and annular fin using the Frobenius expanding series, simplifying assumptions like of arc idealization and insulated fin tip condition have been relaxed and a linear variation of the convective heat transfer coefficient along the fin surface has been taken into account.

Unal [3] studied the effect of variable heat transfer coefficient on the efficiency and the effectiveness for the straight fins. The heat transfer coefficient was assume to depend on the fin surface temperature according to:

$\mathrm{h}=\mathrm{a}_{1} \mathrm{~T}^{\mathrm{n}_{1}}$

Where $a_{1}$ and $n_{1}$ are constants. It was concluded that the decay in the temperature along the fin led to a reduction in the efficiency and effectiveness.

Kahwaji [4] conducted a numerical and electrical analogue study of the thermal performance of annular fins of constant thickness under the one and two dimensional heat flow assumption. He suggested a new simple method for correlating the fin rate of heat transfer which depends on the grouping of the different thermal resistances of the fin in a (driving force / resistance) form model. The suggested resistance is given as:

$$
\mathrm{TR}_{\text {the }}=\left(\left(\frac{\ln \left(\mathrm{r}_{\mathrm{o}} / \mathrm{r}_{\mathrm{i}}\right)}{2 \pi \mathrm{kW}}\right)^{2}+\left(\frac{\mathrm{W}}{4 \pi \mathrm{k}\left(\mathrm{r}_{\mathrm{o}}{ }^{2}-\mathrm{r}_{\mathrm{i}}{ }^{2}\right)}\right)^{2}\right)^{\frac{1}{2}}+\frac{1}{2 \pi \mathrm{ha}\left(\mathrm{r}_{\mathrm{o}}{ }^{2}-\mathrm{r}_{\mathrm{i}}{ }^{2}\right)}
$$


Where $\mathrm{TR}_{\mathrm{th}}$ is the total resistance of the fin and the term under the sequare root is the two - dimensional material resistance while the other term is the surface resistance. The above form of correlation was found to give an accurate representation of the heat transfer from the fin. Moreover, the assumption of one - dimensional heat flow through the fin was found to be valid when the total resistance is greater than $835^{\circ} \mathrm{C} / \mathrm{kW}$.

Al-Makhyoul [5] conducted detailed experiments to validate the above resistance model experimentally. The experiments covered both the natural and forced convection heat transfer modes using fins of different materials and dimensions. The results indicated a good agreement between the suggested model and the experimental findings where the calculated and measured heat fluxs were found to be within less than $(8.33 \%)$ in the natural convection tests and $(11 \%)$ in the forced convection tests.

Kahwaji and Al-Makhyoul [6] derived analytically the total resistance model using the variable heat transfer coefficient in two dimensional heat flow for annular fin constant thickness, the model which has been derived can gives as:

$\mathrm{TR}_{\text {the }}=\sqrt{\left[\left(\frac{\ln \left(\mathrm{r}_{\mathrm{o}} / \mathrm{r}_{\mathrm{i}}\right)}{2 \pi \mathrm{KW}}\right)^{2}+\left(\frac{\mathrm{W}}{4 \pi \mathrm{K}\left(\mathrm{r}_{\mathrm{o}}{ }^{2}-\mathrm{r}_{\mathrm{i}}{ }^{2}\right)}\right)^{2}\right]}+\frac{3\left(\mathrm{r}_{\mathrm{o}}-\mathrm{r}_{\mathrm{i}}\right)}{\mathrm{ka} \pi *\left(4 \mathrm{r}_{\mathrm{o}}{ }^{2}-6 \mathrm{r}_{\mathrm{o}}{ }^{2} \mathrm{r}_{\mathrm{i}}+2 \mathrm{r}_{\mathrm{i}}{ }^{3}\right)}$

where $\mathrm{ka}$ is a term contain the heat transfer coefficient .

The variable distribution of heat transfer coefficient formula has taken from Imre and Razelos [7] in this work. The numerical solution for two dimensional heat flow using a finite difference technique was investigated to prove the validity of the model above and to covered a wide range of heat transfer coefficient, lengths and thicknesses. The results indicated a good agreement between the suggestion model and the numerical solution 
Kahwaji and Al-Niamey [8] investigated the outlines experimentally of the total resistance model suggested by [4] for the heat dissipation when applied to longitudinal fin when the heat transfer coefficient was constant, and given the model as:

$\mathrm{TR}_{\text {the }}=\sqrt{\left(\mathrm{R}_{\mathrm{L}}\right)^{2}+\left(\mathrm{R}_{\mathrm{t}}\right)^{2}}+\mathrm{R}_{\mathrm{S}}$

The study was covered the natural and forced convection heat transfer in order to cover the wide range of heat transfer coefficient, lengths, thicknesses and heat flux. A finite difference technique was used to prove the validity of the experimental results. Finally the results proved the validity of the suggestion model where the maximum difference between the experimental and the numerical solutions was $8.6 \%$ and $14 \%$ in the natural and forced convection experiments respectively.

In this paper, a method for incorporating variable heat transfer coefficients in the total resistance model for longitudinal fin will be derived analytically and its validity will be numerically investigated over a wide range of fins variables and different convection heat transfer coefficient models using three types of distributions as power, exponential and linear in equations $(1,2,3)$.

\section{The numerical solution:}

Certain particular equation applies for every type of fin. These equations were all derived from the general heat conduction equation under different simplifying assumptions and boundary conditions. The general, commonly used assumptions are:

1-The heat flow and temperature distributions through out the fin are independent of time.

2-The fin material is homogenous.

3-There is no heat source inside the fin.

4-The heat flow from the fin surface at any point is directly proportional to the temperature difference between the surface and surrounding fluid at that point. 
5 -the thermal conductivity of the fin material is constant.

6-The heat transfer coefficient is constant or variable along the fin surface.

7-the temperature of the surrounding fluid is constant.

8 -the base of the fin is isothermal.

These assumptions, coupled with the two-dimensional conduction equation in polar coordinates are to be solved numerically in order to investigate the validity of the total resistance model with the variable heat transfer coefficient incorporated in it.

The fin was divided to the radial and transverse directions in to $(\mathrm{N}$ and M) from divisions. Thickness of each one was ( $\Delta x$ and $\Delta y)$ in the radial and transverse directions. The general equation for the temperature distribution in the two dimensional heat flow case can be shown as:

$$
\frac{\partial^{2} \mathrm{~T}}{\partial \mathrm{x}^{2}}+\frac{\partial^{2} \mathrm{~T}}{\partial \mathrm{y}^{2}}=0.0
$$

To calculate the temperature distribution for the inner nodes, we needed to open the first and second derivative for Tyler series and substitute in the equation above as:

$$
T(i, j)=\frac{\left(\frac{T(i+1, j)+T(i-1, j)}{\Delta x^{2}}+\frac{T(i, j+1)+T(i, j-1)}{\Delta y^{2}}\right)}{2\left(\frac{1}{\Delta x^{2}}+\frac{1}{\Delta y^{2}}\right)}
$$

When $1<\mathrm{i}<\mathrm{N}$ and $1<\mathrm{j}<\mathrm{M}$

To calculate the nodes for the temperature distribution in the tip of fin, we must be used the backward difference for Tyler series as:

$-K \frac{\partial T}{\partial x}=h a\left(T(i, N)-T_{f}\right)$

and then

$$
T(N, j)=\frac{\frac{(4 T(N-1, j)-T(N-2, j))}{2 \Delta x}+\frac{h T_{f}}{K}}{\frac{h}{K}+\frac{3}{2 \Delta x}}
$$


when $\mathrm{i}=\mathrm{N}$ and $1<\mathrm{j}<\mathrm{M}-1$

The temperature distribution in the axis which divided the fin to two similar parts can be investigate as:

$\frac{\partial \mathrm{T}}{\partial \mathrm{y}}=0.0$

...(12)

$\mathrm{T}(\mathrm{i}, 1)=\frac{4 \mathrm{~T}(\mathrm{i}, 2)-\mathrm{T}(\mathrm{i}, 3)}{3}$

...(13)

When $2<\mathrm{i}<\mathrm{N}-1$

The temperature distribution along the fin surface can be calculate depending on the variable heat transfer coefficient which shown in equations $(1,2,3)$

$-\mathrm{K} \frac{\partial \mathrm{T}}{\partial \mathrm{y}}=\mathrm{h}\left(\mathrm{T}(\mathrm{i}, \mathrm{j})-\mathrm{T}_{\mathrm{f}}\right)$

$\mathrm{h}=\mathrm{ha} * \mathrm{~h}(\mathrm{I})$

$\mathrm{T}(\mathrm{i}, \mathrm{M})=\frac{\frac{(4(\mathrm{~T}(\mathrm{i}, \mathrm{M}-1)-\mathrm{T}(\mathrm{i}, \mathrm{M}-2))}{2 \Delta \mathrm{y}}+\frac{\mathrm{hT}_{\mathrm{f}}}{\mathrm{K}}}{\frac{\mathrm{h}}{\mathrm{K}}+\frac{3}{(2 \Delta \mathrm{y})}}$

when $2<\mathrm{i}<\mathrm{N}-1$ and $\mathrm{j}=\mathrm{M}$

The temperature distribution in the corner could be calculated:

$\mathrm{T}(\mathrm{N}, \mathrm{M})=\frac{\mathrm{T}(\mathrm{N}-1, \mathrm{M})+\mathrm{T}(\mathrm{N}, \mathrm{M}-1)}{2}$

...(16)

The heat transfer from the fin calculated as:

$\mathrm{QF}=2 \sum_{\mathrm{i}=1}^{\mathrm{i}=\mathrm{N}} \mathrm{H}(\mathrm{i}) * \mathrm{~L} * \operatorname{Dx}(\mathrm{i}) *\left(\mathrm{~T}(\mathrm{i}, \mathrm{M})-\mathrm{T}_{\mathrm{f}}\right)$

...(17)

the maximum heat transfer from the fin was gives as:

$\operatorname{QMax}=2 \sum_{\mathrm{i}=1}^{\mathrm{i}=\mathrm{N}} \mathrm{H}(\mathrm{i}) * \mathrm{~L} * \mathrm{Dx}(\mathrm{i}) *\left(\mathrm{~T}(1,1)-\mathrm{T}_{\mathrm{f}}\right)$

The fin efficiency using the variable heat transfer coefficient was calculated as: 
$\eta=\frac{\mathrm{QF}}{\mathrm{QMax}}$

...(19)

\section{Analysis :}

The heat transfer for longitudinal fin constant thickness can calculated as [4] and given as:

$\mathrm{Q}_{\text {the }}=\frac{\mathrm{T}_{\mathrm{b}}-\mathrm{T}_{\mathrm{f}}}{\mathrm{TR}_{\text {the }}}$

...(20)

where :

$\mathrm{TR}_{\text {the }}=\sqrt{\left(\mathrm{R}_{\mathrm{L}}\right)^{2}+\left(\mathrm{R}_{\mathrm{t}}\right)^{2}}+\mathrm{R}_{\mathrm{S}}$

...(21)

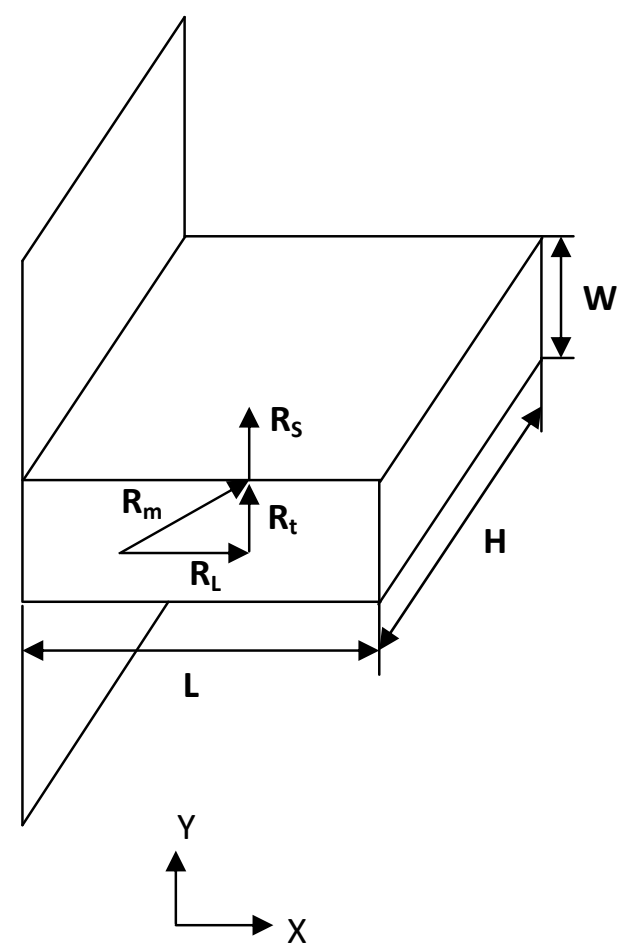

Figure (1) represent the two dimensional analysis of longitudinal fin 
When applied the total resistance model on the longitudinal fin the model will be as:

$\mathrm{TR}_{\text {the }}=\sqrt{\left(\frac{\mathrm{L}}{\mathrm{KHW}}\right)^{2}+\left(\frac{\mathrm{W}}{4 \mathrm{KHL}}\right)^{2}}+\frac{1}{2 \mathrm{haHL}}$

The fin efficiency using the variable heat transfer coefficient can be compute numerically depending on the equations $(1,2,3)$ and given as:

$\eta=\frac{\mathrm{QF}}{\mathrm{QMax}}$

Finally to compute the heat transfer using variable heat transfer coefficient analytically, we can find a new formula depending on the total resistance model in (22)and the fin efficiency in (23) therefore, the heat transfer calculation is given by :

$$
\mathrm{Q}_{\text {the }}=\frac{\mathrm{T}_{\mathrm{b}}-\mathrm{T}_{\mathrm{f}}}{\mathrm{TR}_{\text {the }} * \eta}
$$

\section{Results and Discussions:}

Figures $(2, a, b, c)$ shown the temperature distribution along the fin using a three types of variable heat transfer coefficient such as a power, linear and exponential distributions. Its clear the behavior of temperature gradient along the fin and the decrease in the temperature value from the base in the root to the tip of fin. Near the root, the convective resistance have a high value when use the variable heat transfer coefficient compare with the value at the constant heat transfer coefficient and then, that led us to conclude the temperature in the root have a big value. The analysis in the tip is opposite, when the material resistance was constant in the variable or constant heat transfer coefficient, the convective resistance in 
the variable heat transfer coefficient was low and then the temperature value was decrease.

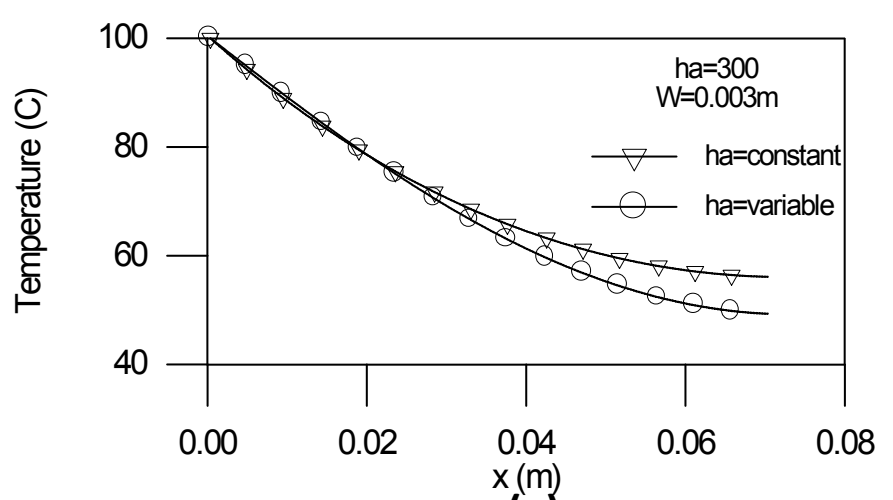

(a)

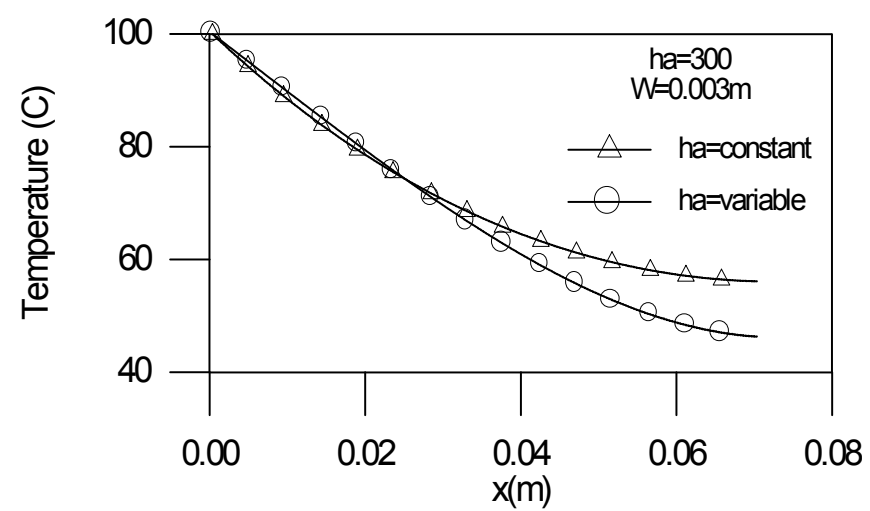

(c)

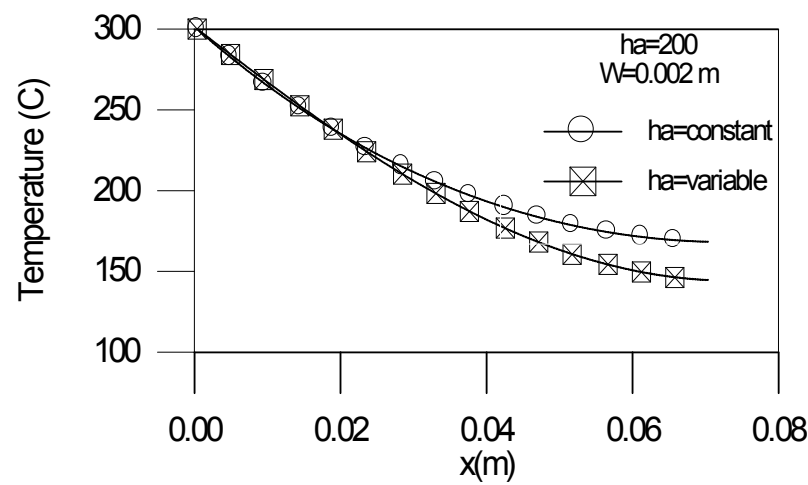

(b)

Figures $(2, a, b, c)$ shown the temperature distribution using power , linear andexponential distributions of heat transfer coefficient

Figures $(3, a, b, c)$ represented the change in the heat flux using a three types of heat transfer coefficient distributions. When the heat transfer coefficient is constant, the heat transfer will increase gradually along the fin because the local heat transfer coefficient remain constant along the fin while the material resistance increase with length. that will causes increase in the temperature gradient and then increase in the heat transfer from the fin.

In the variable heat transfer coefficient, the heat transfer will increase gradually and then decrease along the fin because the increases will happen in the material resistance and the local convective resistance.

When the fin is short, the effect of conductance resistance will be high and then increase in the heat transfer. Along the fin the heat transfer will decrease because the increase in the local convective resistance near the root and the local convective resistance will decrease and then the convective resistance will be more effect than the material resistance, that's led to decreases in the heat transfer. 


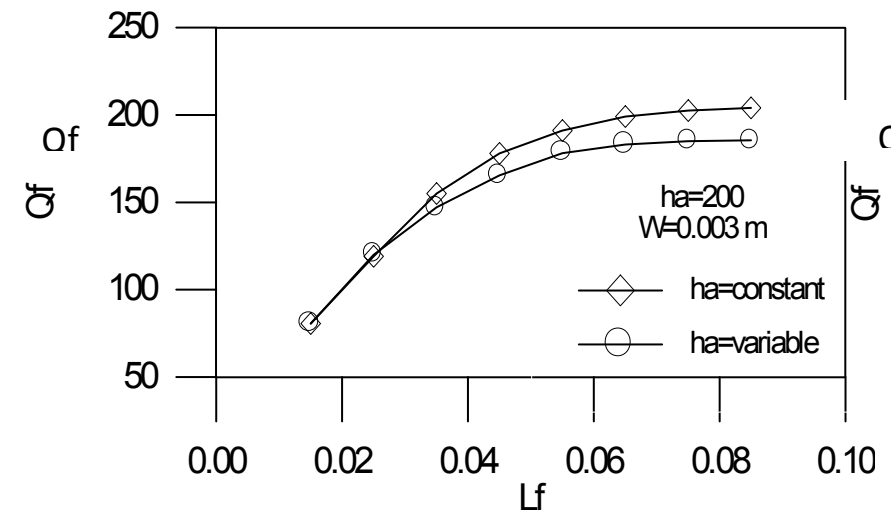

(a)

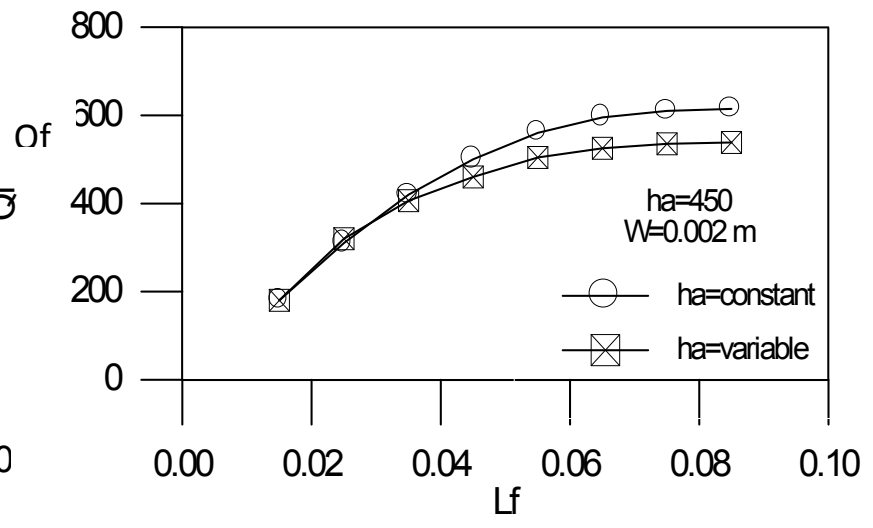

(b)

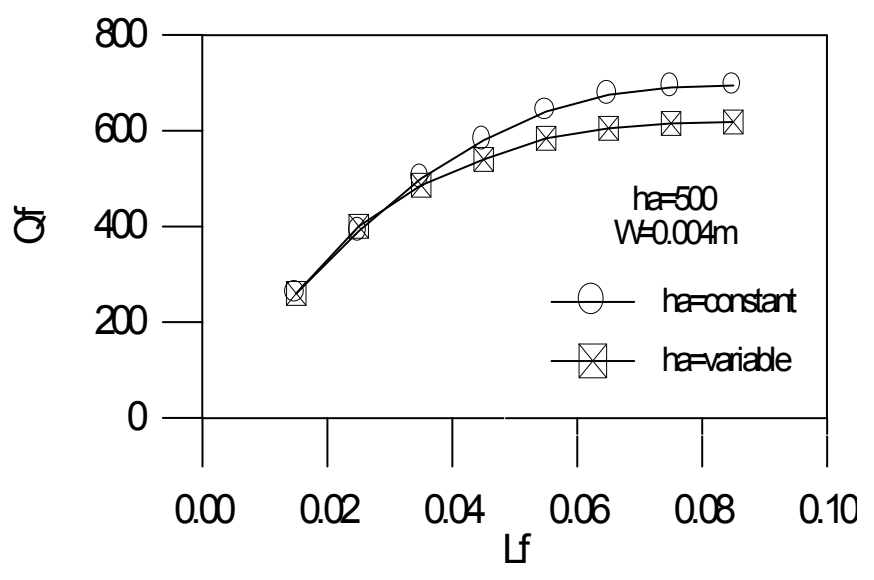

Figures $(3, a, b, c)$ shown the Relation between heat transfer and fin length using power,linear and exponential distribution of heat transfer coefficient

Figure (4) shows the heat transfer results which computed numerical and analytical and plotted together. All points fell on the same straight line which indicates the sufficiency of the proposed model and it's adequacy to describe the phenomena of heat transfer through longitudinal fins. The agreement between the suggested model, the experimental results and the numerical model is also in good agreement. Extending the numerical model results and suggested model results beyond the experiment range shows good agreement between them as shown in this figures. This further substantiates the validity of the suggested model.

Figures $(3, a, b, c)$ shown the relation between heat transfer and fin length using

power, linear and exponential distributions of heat transfer coefficient 


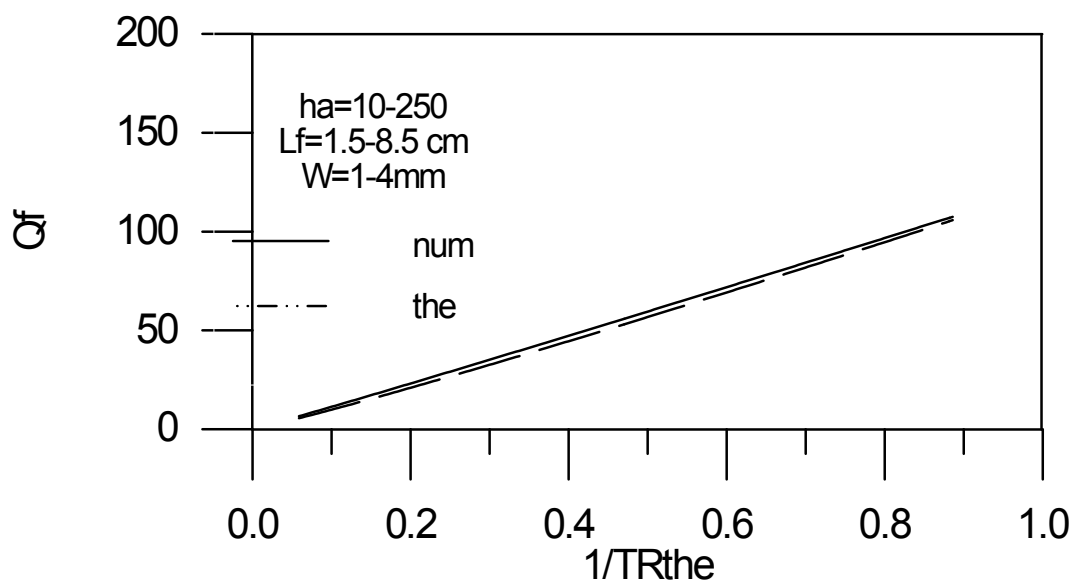

Figures (4) The linear variation of the heat dissipation with the total resistance

using power , linear and exponential distributions of heat transfer coefficient

Figure (5) shown the relation between the surface resistance with length of fin using the a power distribution of heat transfer coefficient. Generally at the same length, the increase in the heat transfer coefficient led to decrease in the distribution value for heat transfer coefficient and then decrease in the convective resistance and finally the surface resistance. At the same heat transfer coefficient, the convective resistance decrease with the fin length because the increase in the fin area and then the decreases in the surface resistance.

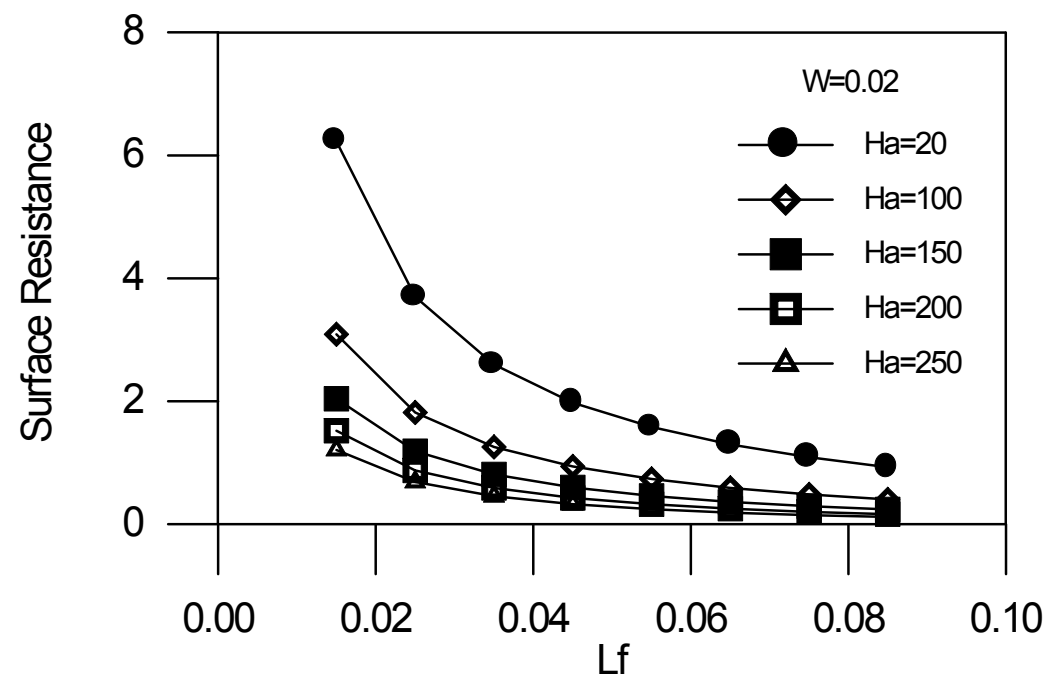

Figure (5) shown surface resistance distribution along the fin 


\section{References:}

1-Kern,D.Q.\& Kuras,A.D ” ‘.Extended Surface Heat Transfer” , Mc Graw-Hill , 1972 .

2-Das,P.K. \& Kunda,B., "Performance Analysis and Optimization of Straight Taper Fins with Variable Heat Transfer Coefficient", Int. J. of Heat and Mass Transfer, pp.4739-4750, August 2002.

3- Badri, S., “ Three Dimensions Analysis and Optimizaion for Annular Fins with

Variable Heat Transfer Coefficient", M Sc. Thesis, University of Mosul, 2003.

4-Kahwaji, G.Y., "An Analogue System for Heat Flow Through Annular Fin Constant Thickness ", M. Sc. Thesis, University of Mosul, 1979.

5-Al-Makhyoul, Z.M., "Experimentally Validation of the Total Resistance Heat Dissipation Model for Heat Transmission Through Annular Fins", M.SC. Thesis, University of Mosul, 2001.

6-Kahwaji, G.Y. \& Al-Makhyoul, Z.M., "Validation of the Total Resistance Heat Dissipation Model for Heat Transmission Through Annular Fins with Variable Heat Transfer Coefficient", J. of Al-Rafideen, Mousl 2005.

7-Razelos, P. \& Imer, K., "The Optimum Dimensions of Circular Fin with Variable Thermal Parameter", ASME, J. of Heat Transfer, v.102,PP420-425,1980.

8-Al-Naimey, R., "Experimental Investigation of Total Resistance and Heat Dissipation from Longitudinal Fins", M.SC Thesis, University of Mosul, 2004.

9-Carnahan, B., Luther, H.A. \& Wilkes, J.O. , " Applied Numerical Method", 1969. 